\title{
Physical habitat quality and interspecific competition interact to influence territory settlement and reproductive success in a cavity nesting bird
}

\author{
John A. Jones*, Morgan R. Harris and Lynn Siefferman
}

Biology Department, Appalachian State University, Boone, NC, USA

Edited by:

Peter Schausberger, University of

Natural Resources and Life

Sciences, Austria

\section{Reviewed by:}

Laura J. May-Collado, University of Vermont, USA

Pierre Bize, University of

Aberdeen, UK

Ricardo Serrão Santos, University of the Azores, Portugal

\section{*Correspondence:}

John A. Jones, Biology Department,

Appalachian State University, 572

Rivers Street, Boone,

NC 28608-2027, USA

e-mail: jonesja2@appstate.edu
Determining how to best measure habitat quality is essential for many conservation plans and basic ecological questions. Territory quality is thought to be a product of physical habitat characteristics (i.e., habitat quality) and the density of competitors yet these relationships are rarely demonstrated. Occupancy rates, or how often a territory has been used since its establishment, are often used as a proxy for habitat quality. We tested the utility of occupancy rates as a proxy of habitat quality by comparing it with reproductive output in eastern bluebirds (Sialia sialis). We then tested the extent to which occupancy rates are influenced by physical habitat quality (land cover via remote sensing), aggressive interspecific competition with tree swallows (Tachycineta bicolor), and the individual quality of the breeding birds. We found that occupancy was the best predictor of reproductive output although female age and habitat openness also contributed to reproductive success. Habitat openness and competition with tree swallows best predicted site occupancy. Bluebirds appeared to avoid settling in areas of higher interspecific competition with tree swallows, but when bluebirds settled in areas of higher interspecific competition, physical (spatial) habitat quality was a good predictor of settlement location. Thus, our results suggest that although historical occupancy of territories is an accurate and easy-to-measure proxy of reproductive output, the realized habitat quality is a product of the tradeoffs between spatial habitat quality and interspecific competition. Here, we show that aggressive interspecific competition interacts with spatial habitat to influence settlement. A better understanding of how these variables influence settlement and productivity may better enable the management of source, rather than sink, habitats.

Keywords: coexistence, conservation, eastern bluebird, habitat preference, individual quality, interspecific competition, occupancy, tree swallow

\section{INTRODUCTION}

Habitat quality influences territory use and reproductive success, thus, assessments of quality are essential to developing successful conservation plans (Johnson, 2007). The physical environment and density of competitors are expected to influence habitat quality, yet these relationships are rarely demonstrated (reviewed in Johnson, 2007) suggesting that elucidating simple and effective methods of measuring habitat quality can be difficult. Furthermore, because habitat parameters and resources within territories are key determinants of individual fitness (Komdeur, 1992), there should be strong selection for individuals to recognize spatial differences in territory quality (Orians and Wittenberger, 1991; Sergio and Newton, 2003), including resource availability, predator abundance, or other factors that influence growth, survivorship or reproductive success (Rosenzweig, 1991; Muller et al., 1997). The ability to assess breeding habitat quality prior to territory establishment is adaptive (Parejo et al., 2007) and could include factors like vegetation structure, resource abundance, and intra- and interspecific densities (Clobert et al., 2001; Parejo et al., 2007). Thus, the attractiveness of a particular territory and the likelihood of securing it depend on the physical quality of the territory, the density of competitors, and the quality of the individual (Johnson, 2007).

Researchers often measure habitat quality directly via food abundance (Penteriani et al., 2002), availability of breeding locations, and predation risk (Sergio and Newton, 2003), or indirectly via survival and reproductive success (Nilsson, 1987; Korpimaki, 1988). These measures are often difficult and expensive to acquire, and thus, other proxies are often employed to quantify habitat quality. For example, in migratory birds, timing of arrival on the nesting grounds is a standard proxy of individual quality, as it often positively correlated with individual quality (i.e., age or body condition), physical habitat quality and reproductive success (Lozano et al., 1996; Kokko, 1999). However, settlement dates may be poor proxies of individual quality in year-round residents because individuals are often present without actively defending a territory, and thus, are harder to detect. Further, it is important to 
consider the consequences of settlement in areas where aggressive competition for nesting locations may lower the realized habitat quality (Johnson, 2007) of a territory or reduce fitness (e.g., Harris and Siefferman, 2014).

Alternatively, historical occupation of a nesting location and physical land-cover type are relatively simple ways of assessing habitat quality. Indeed, occupation ratios (the number of years a territory is occupied by a particular species since establishment) correlate positively with habitat quality in at least 20 avian species (reviewed in Sergio and Newton, 2003; Doran and Holmes, 2005; Dawson and Bortolotti, 2006; Janiszewski et al., 2013). Further, researchers have found that arrival dates (and settlement time) correlate with occupancy rates (Askenmo, 1984; Matthysen, 1990; Sergio and Newton, 2003). Using historical occupation rates is logical in box-nesting species as these data are easy to obtain. Previous research has shown that, when selecting territories, individuals can use available public information surrounding an area to recognize the spatial differences in territory quality (Doligez et al., 2002). Additionally, animals can balance the potential resource value (e.g., habitat quality) of a territory with conspecific competition (Johnson, 2007). However, to our knowledge, no study has investigated interactions between aggressive interspecific competition and physical habitat characteristics on occupancy rates and reproductive success. If sympatric species aggressively compete over shared limited resources, there may be tradeoffs between settling in areas of higher resource abundance and areas with increased competition.

Here, we used 4 years of eastern bluebird (Sialia sialis) breeding data to investigate the influence of physical habitat quality and aggressive interspecific competition on their settlement patterns and reproductive success. First, we determined how often territories (i.e., individual nest boxes) are used and to establish whether territory use is non-random. We then investigated the utility of occupancy rates as a proxy of habitat quality by testing whether territories used more often (high-occupancy territories) produce more fledglings annually. We also investigated how physical habitat, density of competitors, and individual quality of bluebirds influenced reproductive success. Because birds that nested in high occupancy nesting sites experienced higher annual reproductive success, we then sought to understand predictors of box occupancy.

Eastern bluebirds are socially monogamous passerines that breed throughout eastern North America (Gowaty and Plissner, 1998). They are obligate secondary cavity nesters and readily use artificial nesting cavities. Bluebirds are partial migrants, in that some populations migrate yearly while others remain in the area (Gowaty and Plissner, 1998). Although we do not know the migration status of our eastern bluebird population, bluebird pairs do not begin to defend territories aggressively until March (pers. obs.). In the southern Appalachians, our bluebirds produce generally one and sometimes two successful clutches per year. Bluebirds are open-habitat specialists that feed primarily on terrestrial arthropods (Gowaty and Plissner, 1998). Because they generally breed in open habitats with sparse understory, drop-foraging accounts for nearly all foraging attempts throughout the breeding season (Pinkowski, 1977). The amount of open land within close proximity of available nesting sites is likely to be extremely important for their reproductive success and potentially an accurate measure of direct habitat quality.

Bluebirds face interspecific competition with other cavity nesting species for nesting locations (Gowaty and Plissner, 1998). In the southern Appalachian Mountains of western NC, bluebirds compete with tree swallows (Tachycineta bicolor), house sparrows (Passer domesticus), Carolina chickadees (Poecile carolinensis) and house wrens (Troglodytes aedon). House wrens occupy $\sim 17 \%$ of occupied nest boxes at our field site but generally settle on territories after most bluebird nesting attempts (Johnson, 1998). Together, chickadees and sparrows represent only $\sim 6 \%$ of occupied nest boxes at our field site. However, bluebirds and tree swallows occupy nearly equal shares of the field site ( $~ 34 \%$ each), and thus, tree swallows are the most abundant competitors for nesting cavities in our field site (authors, pers. obs.).

Here we focus on whether competition with tree swallows for nest cavities influences habitat quality for bluebirds. Tree swallows represent a relatively new selection pressure to bluebirds in our field site, as this species has recently expanded its breeding range south and has bred in the southern Appalachian Mountains for $<40$ years (Wagner et al., 2002). Indeed, our field site is a mosaic of areas where male and female bluebirds and tree swallows aggressively compete for nesting sites and areas where bluebirds breed with little interaction from tree swallows. Tree swallows are aerial insectivores (Robertson et al., 1992), and thus, competition for food resources between swallows and bluebirds is limited. However, tree swallows and bluebirds compete aggressively for nesting cavities and this competition has a greater effect on bluebird breeding success than conspecific competition (Harris and Siefferman, 2014). Moreover, bluebirds may have difficulty in assessing potential competition levels, as tree swallows begin breeding approximately 1 month after bluebirds and swallows arrive on the breeding grounds a few weeks prior to bluebird egg laying (Robertson et al., 1992; Gowaty and Plissner, 1998; authors, pers. obs.). Although intraspecific competition likely plays an important role on territorial settlement of eastern bluebirds (Siefferman and Hill, 2005a), post-settlement aggressive behaviors between conspecifics are uncommon (Harris and Siefferman, 2014).

\section{MATERIALS AND METHODS GENERAL FIELD METHODS}

Since 2009, we have monitored $\sim 200$ nest boxes for eastern bluebird and tree swallow populations in Watauga County, NC. This bluebird population breeds from mid-April to early August in the southern Appalachians. All eastern bluebird nests were monitored and all adults and offspring were marked with numbered U.S.G.S. bands each field season. Additionally, we estimated the age of all newly banded adults as either yearling (in their first year of life) or in the second or subsequent year based on the shape of the 10 th primary feather (Pitts, 1985). We have an annual return rate of $\sim 35 \%$ of bluebirds at our field sites, and thus, we knew the exact age of recaptured birds. For each bird, we measured mass $( \pm 0.5 \mathrm{~g})$, wing length $( \pm 0.5 \mathrm{~mm})$ and we used the residuals of a mass to wing regression as an index of body condition (Jakob et al., 1996). We monitored nests and quantified reproductive output as the total number of fledglings per breeding season and also 
recorded first egg date, clutch size and the number of clutches produced per pair.

Using the occupancy data of bluebirds per box over four breeding seasons (2009-2012) we determined the occupancy rate of each box (boxes were given a score of 0-4 depending on number of years the box was used).

\section{DETERMINATION OF COMPETITION LEVEL}

The field site includes five distinct spatial clusters of nest boxes, hereafter referred to as "zones." Following the methods of Harris and Siefferman (2014), we defined zones as areas where nest boxes are $<0.50 \mathrm{~km}$ apart (mean distance between boxes in a zone $=0.15 \mathrm{~km}$ ) and zones are separated by $>1 \mathrm{~km}$ (mean distance between zones $=1.32 \mathrm{~km}$ ). High and low competition sites were assigned based on historical occupancy rates of bluebirds and tree swallows, as they are the most abundant and aggressive competitors with bluebirds in our field site (authors, pers. obs.). From data collected over 4 years, (2009-2012) we assessed occupancy rates per nest box for both bluebirds and tree swallows. The data were then averaged independently over 4 years to calculate occupancy rates for each species. We performed chi-squared analyses to determine if there were differences in historical occupancy by eastern bluebirds and tree swallows in each zone over the past 4 years. When a zone had either higher abundances of tree swallows or no significant difference between bluebird and tree swallow occupancy, it was considered a location of high interspecific competition; when a zone exhibited significantly higher occupancy rates by eastern bluebirds, it was considered a location of low interspecific competition (Figure 1). One zone had a higher abundance of other species (house sparrows) than eastern bluebirds so this zone was excluded from analyses of competition.

\section{DIRECT MEASURE OF HABITAT QUALITY}

We define physical (spatial) habitat quality by the amount of open agriculture and grassland, termed "openness." We performed an unsupervised classification in ERDAS Imagine (Leica Geosystems, Atlanta, GA, USA) on ASTER imagery from October 2012 (LP DAAC) to distinguish between open grassland/agriculture and all other land-cover types. We then imported the classified image into ArcGIS 10 (ESRI, 2011) to calculate the amount of open area within a $75 \mathrm{~m}$ radius $\left(17,775 \mathrm{~m}^{2}\right.$; Gowaty and Plissner, 1998) buffer for each nest box territory by multiplying the number of pixels classified as open area/agriculture by the spatial resolution $(15 \times 15 \mathrm{~m})$. The total open area was then converted to percent open area in each territory for further analyses.

\section{STATISTICAL ANALYSIS}

Statistical analyses were performed in SPSS v.21.0 (IBM Corp, 2012). To investigate whether bluebirds settled on territories in a non-random manner, we tested for a Poisson pattern of expected occurrence (Sergio and Newton, 2003).

For the reproductive output dataset, because the lowoccupancy boxes were rarely used while high-occupancy territories were commonly used, we randomly selected 1 year for analyses when boxes were used $>1$ year $(n=129)$. For this year, we also used body condition and age measurements of male and female bluebirds that occupied that nest box. We found no year effect on bluebird condition or annual reproductive output. To determine predictors of reproductive output, we used a generalized linear model with total annual number of young fledged as the dependent variable and occupancy, openness, interspecific competition, and measures of male and female bluebird

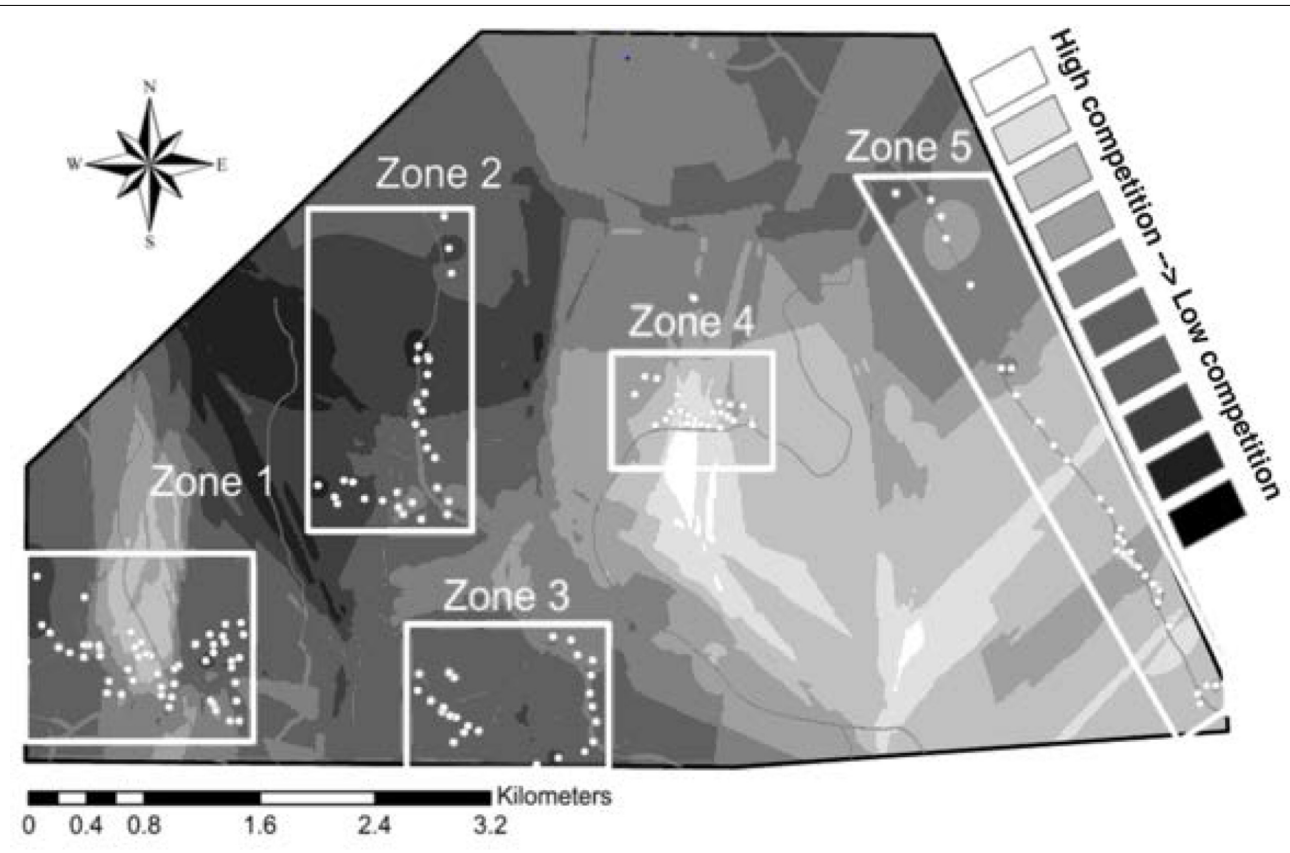

FIGURE 1 | Interpolation of the occupancy ratios of eastern bluebirds to tree swallows throughout the field site. The ratio is: bluebird occupancy rate over the past 4 years/tree swallow-occupancy rate of the past 4 years. Low-competition sites: Zone 2 and Zone 3; high-competition sites: Zones 1, 4, and 5. 
characteristics as independent variables. We ran an additionally generalized linear model to determine the importance of laying date, clutch size and number of clutches per season on the number of offspring produced. For each of these questions, we used Akaike's information criterion (AIC) model fitting procedures to choose the best model (Burnham and Anderson, 2002). We ran all models first with interaction terms present and if the interaction term was not statistically significant, it was removed. Finally, because occupancy was the best predictor of fledging success and number of clutches was the best predictor of reproductive output, we directly tested whether occupancy predicted the likelihood that a particular nest box would host two clutches in a season using a logistic regression (generalized linear model: binary logistic).

To determine the best predictors of occupancy, we used a generalized linear model with occupancy as the dependent variable and percent open area and interspecific competition as independent variables. In this dataset, we incorporated all boxes in the dataset but excluded individual bird characteristics because some nest boxes were never used by bluebirds. We used AIC model fitting procedures to choose the best model. Again, all models first included interaction terms and those were removed if not statistically significant.

\section{ETHICS STATEMENT}

Our study was carried out in accordance to the recommendations set forth by the Institutional Animal Care and Use Committee of Appalachian State University (IACUC; permit number: 12-09). Each banded bird was handled in such a way to reduce stress and avoid physical harm (US banding permit number: 23563).

\section{RESULTS}

\section{DISTRIBUTION OF INTERSPECIFIC COMPETITION}

In zones 1 and 5 (Figure 1), bluebirds and tree swallows were statistically equally likely to occupy nest boxes [Zone 1: $X_{(1)}^{2}=$ 3.09, $P=0.08$; Zone 5: $X_{(1)}^{2}=2.28, P=0.13$ ]. In zones 2 and 3 (Figure 1), bluebirds were significantly more likely to occupy the nest boxes than swallows [Zone 2: $X_{(1)}^{2}=13.79, P<0.001$; Zone 3: $X_{(1)}^{2}=7.81, P=0.005$ ]. In zone 4 (Figure 1) swallows were significantly more likely to occupy the nest boxes than bluebirds $\left[X_{(1)}^{2}=4.27, P=0.04\right]$. Therefore, zones 2 and 3 were designated as areas with low interspecific competition and zones 1, 4, and 5 were designated as areas with high interspecific competition.

\section{EASTERN BLUEBIRD OCCURRENCE PATTERNS}

Between the 2009-2012 field seasons, 129 nest boxes were occupied by eastern bluebirds at least one time (see Table 1 for the

Table 1 | Summary table of boxes used throughout our study site in various competition zones.

\begin{tabular}{lccccc}
\hline Number of years occupied: & $\mathbf{0}$ & $\mathbf{1}$ & $\mathbf{2}$ & $\mathbf{3}$ & $\mathbf{4}$ \\
\hline High competition & 36 & 24 & 15 & 12 & 14 \\
Low competition & 4 & 17 & 9 & 20 & 3 \\
\hline
\end{tabular}

distribution of occupancy and competition level across the field site). The distribution of bluebird occupancy was marginally significantly different from a Poisson pattern of occurrence $(P=0.07)$.

\section{REPRODUCTIVE OUTPUT}

Overall, $37.61 \pm 24.87 \%$ of the area within bluebird territories was classified as open (grassland/agriculture). After model selection, the best fitting model to explain reproductive output included percentage of open habitat, female age, and occupancy [likelihood $X_{(3,77)}^{2}=15.903, P=0.001, w_{\mathrm{i}}=0.98$; Table 2]. In this model, the only variable to have a significant main effect was occupancy $(P=0.001)$. More bluebird nestlings fledged at territories of high historical occupancy compared to low occupancy territories [Wald $X_{(1,129)}^{2}=25.75, P<0.001$; Figure 2]. Tukey's comparison tests revealed that there were significantly fewer nestlings fledged per territory in infrequently used boxes ( 1 or 2 years total) vs. those historically occupied often ( 3 or 4 years total; $P<0.03$ ). Additionally, we found non-significant trends suggesting that more offspring fledged from nest boxes in more open habitats [Wald $X_{(1,126)}^{2}=2.78, P=0.10$ ] and when reared by older female bluebirds [Wald $X_{(1,80)}^{2}=3.50$, $P=0.06]$. We found no relationship between reproductive success interspecific competition level [Wald $X_{(1,114)}^{2}=0.48$, $P=0.49]$.

The best model to predict the number of offspring fledged based on nest-specific characteristics was one that included clutch size, the number of clutches produced in a year, and first egg dates [Wald $X_{(1,110)}^{2}=23.85, P<0.001$; Table 3]. Pairs produced more fledglings per year when females laid larger clutches and produced two clutches, rather than one. However, despite its importance in the best fitting model, laying date was not statistically significant [Wald $X_{(1,113)}^{2}=0.36, P=0.55$ ]. Moreover, logistic regression revealed that bluebirds were significantly more likely to have two clutches at boxes of higher occupancy [Occupancy rates for 1 clutch: $0.51 \pm 0.26$; 2 clutches: $0.67 \pm 0.27$; Wald $\left.X_{(1,121)}^{2}=7.17, P=0.01\right]$.

Table 2 | Model selection of the significant variables that influence reproductive success in the eastern bluebird population of western NC.

\begin{tabular}{lcccc}
\hline Model & $\boldsymbol{\Delta A I C}$ & $\boldsymbol{w}_{\boldsymbol{i}}$ & Likelihood $\boldsymbol{X}^{\mathbf{2}}$ & $\boldsymbol{P}$ \\
\hline Occupancy & 242.0 & 0.00 & 23.48 & $<0.001$ \\
Female age & 22.60 & 0.00 & 3.43 & 0.064 \\
\% Open habitat & 248.9 & 0.00 & 2.75 & 0.097 \\
Occupancy, Female age & 11.30 & 0.00 & 16.71 & $<0.001$ \\
\% Open habitat, Occupancy & 231.3 & 0.00 & 22.38 & $<0.001$ \\
\% Open habitat, Female age & 8.20 & 0.02 & 5.70 & 0.06 \\
\% Open habitat, Female age, & 0.00 & 0.98 & 15.90 & 0.001 \\
Occupancy & & & &
\end{tabular}

The percent of open habitat, female age, and occupancy are the strongest model; however, occupancy is the only variable within this model to have a significant main effect. $\triangle A I C$ is the change in Akaike information criterion; $w_{i}$ is the Akaike weight. 


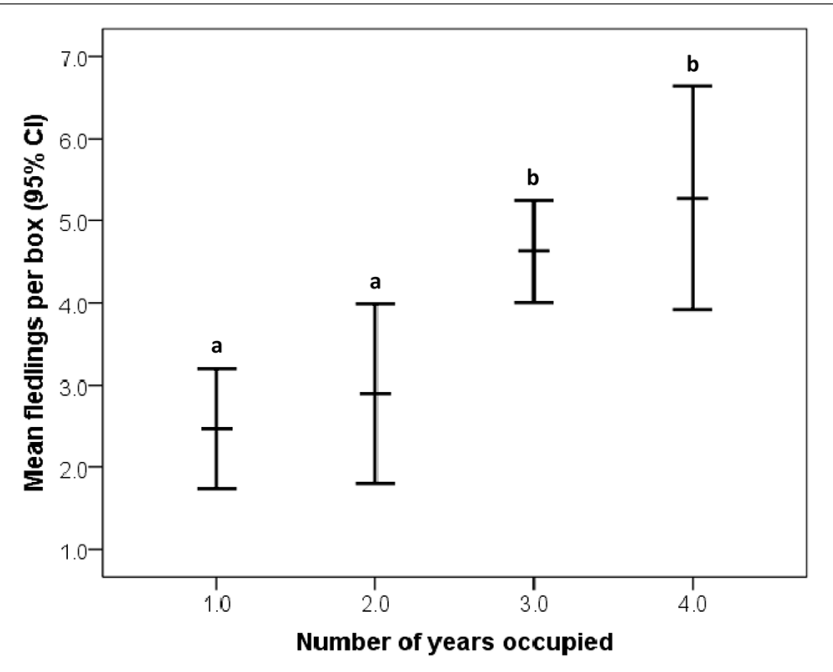

FIGURE 2 | Relationship between historical occupancy and reproductive success (annual number of fledglings per territory) in eastern bluebirds $(\mathbf{9 5 \%} \mathbf{C l}$ for the mean). Significant $(P<0.05)$ post-hoc differences are designated by letters $(a, b)$.

Table 3 | Model selection of the nest-specific significant variables that influence reproductive success.

\begin{tabular}{lrccc}
\hline Model & $\boldsymbol{\Delta A I C}$ & $\boldsymbol{w}_{\boldsymbol{i}}$ & Likelihood $\boldsymbol{X}^{\mathbf{2}}$ & $\boldsymbol{P}$ \\
\hline Clutch size & 68.15 & 0.00 & 10.80 & 0.001 \\
Number of clutches & 50.93 & 0.00 & 23.87 & $<0.001$ \\
First egg date & 35.07 & 0.00 & 0.04 & 0.85 \\
$\begin{array}{l}\text { Clutch size, Number of } \\
\text { clutches }\end{array}$ & 38.59 & 0.00 & 32.51 & $<0.001$ \\
$\begin{array}{l}\text { Clutch size, First egg date } \\
\text { First egg date, Number of }\end{array}$ & 24.25 & 0.00 & 7.29 & 0.03 \\
$\begin{array}{l}\text { clutches } \\
\text { Clutch size, First egg date, }\end{array}$ & 0.00 & 0.01 & 17.50 & $<0.001$ \\
Number of clutches & & & & \\
\end{tabular}

Clutch size, first egg date, and the number of clutches was the strongest model; however, the first egg date was not a significant main effect in the model. $\triangle \mathrm{AIC}$ is the change in Akaike information criterion; $w_{i}$ is the Akaike weight.

\section{INFLUENCE OF HABITAT AND COMPETITION ON BLUEBIRD SETTLEMENT}

After model selection, the best fitting model to explain historical occupancy included a significant interaction between effects of openness and interspecific competition [Wald $X_{(1,154)}^{2}=$ $8.85, P=0.003]$, thus we separated the occupancy dataset by interspecific competition level. We found that there was no significant effect of openness on occupancy in low competition zones [Wald $X_{(1,53)}^{2}=0.28, P=0.60$; Figure 3A]. However, in high competition zones, territories with a greater percentage of open habitat were occupied more often by bluebirds $\left[\right.$ Wald $X_{(1,107)}^{2}=25.59, P<0.001$; Figure 3B . Furthermore, we found significantly higher bluebird occupancy rates in zones of low compared to high interspecific competition [Wald $X_{(1,159)}^{2}$, $P=0.01$, Figure $4 \mathrm{~A}]$. We also found that nest boxes in low

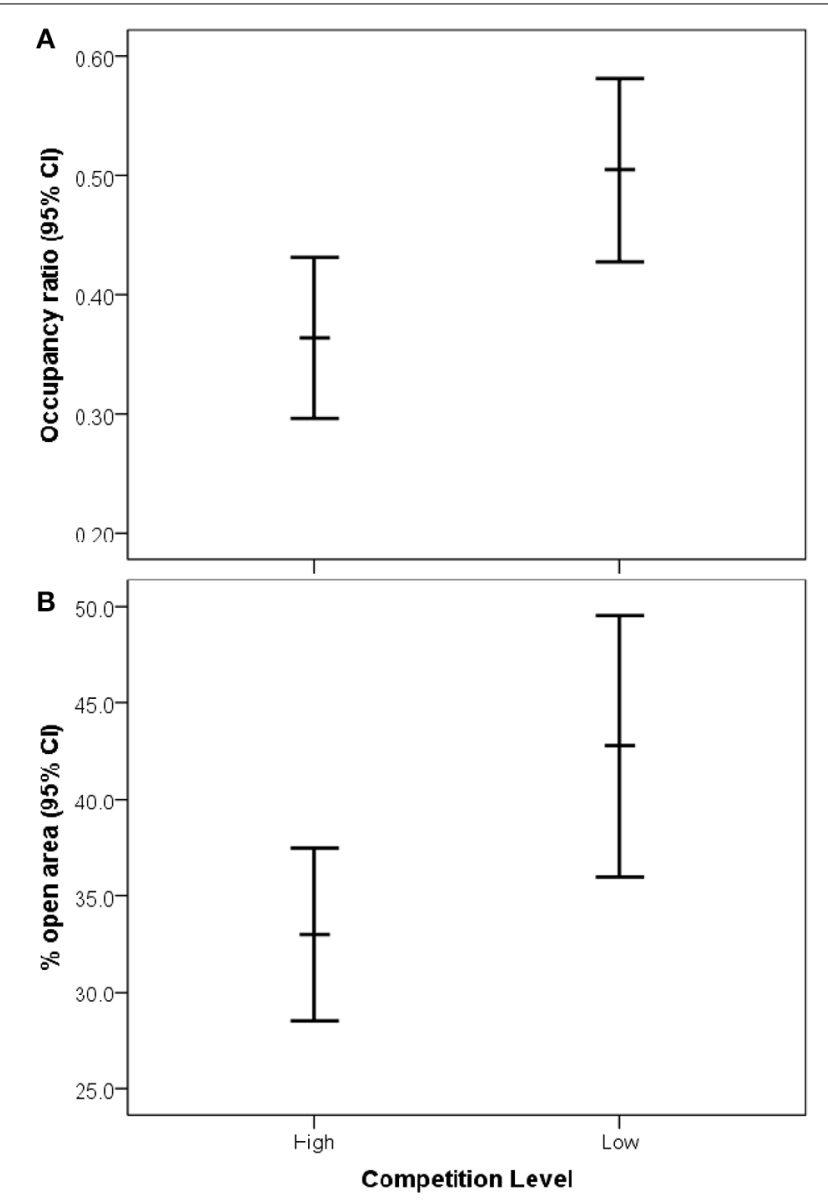

FIGURE 3 | Relationship between (A) eastern bluebird occupancy (number of years occupied) and (B) percentage of open area (grassland/agriculture) within bluebird territories in low and high competition zones on settlement ( $95 \% \mathrm{Cl}$ for the mean).

interspecific competition zones had a greater area designated as open (open grassland/agriculture) compared to those occurring in high interspecific competition zones [Wald $X_{(1,160)}^{2}=5.69$, $P=0.02$, Figure $4 \mathrm{~B}]$.

\section{DISCUSSION}

Our results suggest that bluebirds settle on territories nonrandomly; both the spatial habitat quality and interspecific competition likely influence settlement because bluebirds are more likely to use open habitats with fewer tree swallows. Further, bluebird settlement patterns suggest an ecological basis for nonrandom nest-site selection that is consistent with other studies (e.g., Askenmo, 1984; Matthysen, 1990; Newton, 1991; Kostrzewa, 1996; Sergio and Newton, 2003). Two lines of evidence suggest that historical occupancy is likely an accurate and easyto-measure proxy of habitat quality in eastern bluebirds: (1) birds that settle on high occupancy nesting territories experience higher annual reproductive success (2) occupancy rates are positively related to the percentage of openness within territories, which also predicts reproductive success. However, occupancy only predicted the percentage of open habitat in high 


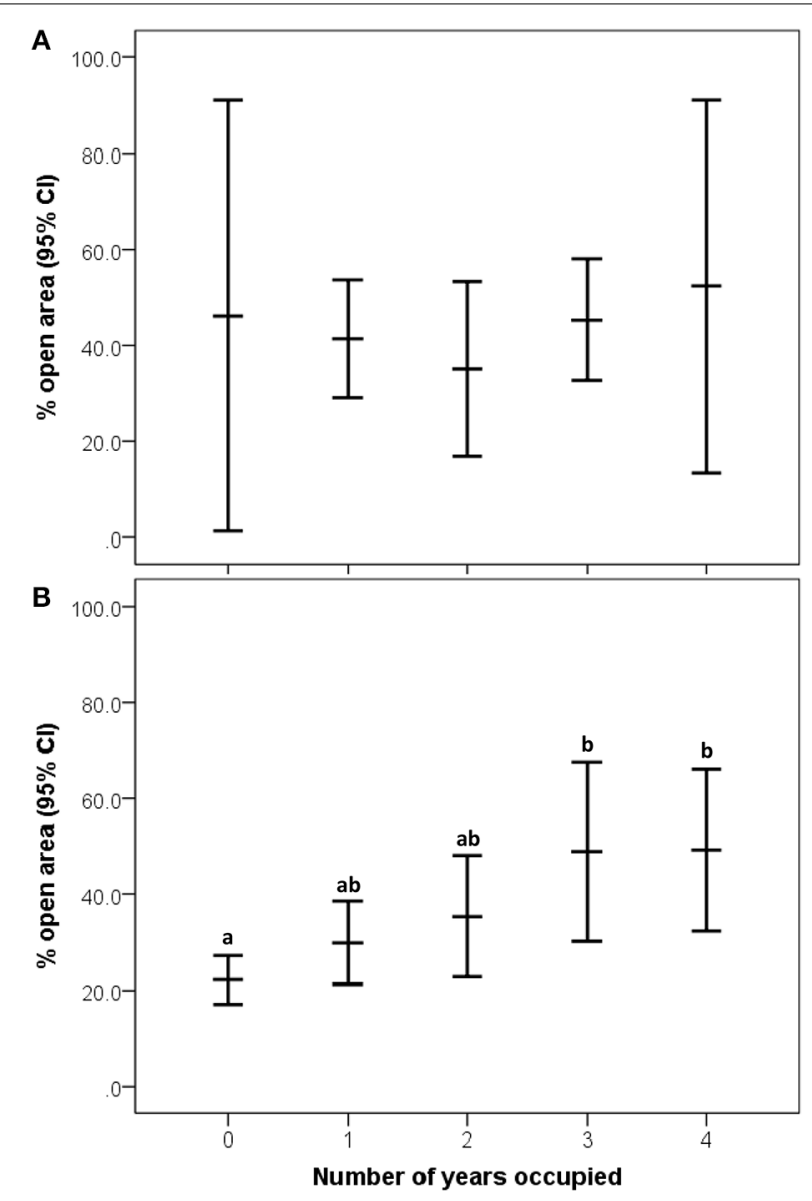

FIGURE 4 | Relationship between level of competition (high vs. low) with tree swallow and $(A)$ bluebird occupancy ratios (the percentage of time a territory is occupied since establishment) and (B) percentage of open area (grassland/agriculture). There is a greater portion of $\%$ open area per territory and higher occupancy at nest boxes in areas of low interspecific competition.

competition environments. Eastern bluebirds appear to be behaviorally subordinate to tree swallows in our population, as tree swallows have a large effect on bluebird reproductive success (Harris and Siefferman, 2014; authors, pers. obs.). Because we found that percent openness only predicted bluebird settlement in areas with increased competition with tree swallows (Figure 3B), it seems likely that selecting territories in more open habitats better allows bluebirds to cope with tree swallow harassment.

Our assessment of higher quality physical habitat parameters appears only to predict territory settlement when bluebirds face aggressive competition with tree swallows. Eastern bluebirds may need higher quality habitats (i.e., more open areas to better see terrestrial arthropods) to cope successfully with tree swallow competition (Gowaty and Plissner, 1998). Although we found no relationship between bluebird body condition and interspecific competition, it may be that only the most aggressive bluebirds can gain high quality breeding sites when competing with tree swallows in open habitats (e.g., Scales et al., 2013). Indeed, early in the breeding season, bluebirds with territories in locations of high interspecific competition defend their territories more aggressively compared to those in low competition zones (Jones, unpubl. data). We found no evidence of reduced reproductive success (number of offspring fledged) in areas of high interspecific competition; however, a previous study found that nestling bluebirds are smaller at fledging age in locations of high interspecific competition (Harris and Siefferman, 2014). The benefits of higher quality spatial habitat may be balanced by the negative effects of high competition and this could result in lower realized habitat quality (i.e., the quality of the habitat actually experienced by competing occupants). Previous research has shown that there is a balance between increased intraspecific competition and habitat quality (Johnson, 2007); our results suggest similar patterns exist for interspecific competition.

Agonistic interactions between bluebirds and tree swallows associated with competition for nesting sites may also result in swallows usurping bluebird nests or even death of adult bluebirds (Hersey, 1933; authors, pers. obs.). We can think of three explanations for why bluebirds do not seem to avoid tree swallows altogether. First, interspecific competition levels are likely difficult for bluebirds to assess during early territory establishment because tree swallows begin nesting approximately 1 month later than bluebirds at our study site (Robertson et al., 1992; Gowaty and Plissner, 1998; authors, pers. obs.). Second, male bluebirds at this field site show flexible territorial aggression (Harris and Siefferman, 2014), suggesting that some individuals are able to successfully increase aggression to combat tree swallow harassment. Third, tree swallows have only recently $(<40$ years) expanded their breeding range to include our field site in the southern Appalachians (Lee, 1993; Wagner et al., 2002). It is possible that selection pressure from tree swallows may eventually lead to a change in the criteria that bluebirds use to choose territories. A study over a larger geographic scale, designed to compare habitat selection between populations of bluebirds that do and do not compete with tree swallows could shed light on these questions.

Although occupancy was a good predictor of reproductive output in our dataset, positive relationships between habitat quality and reproductive output can be confounded by individual quality because higher-quality individuals should settle preferentially in the most productive sites (Fretwell, 1972; Lomnicki, 1988). Indeed, it is difficult to separate the effects of individual quality and habitat quality on fitness in natural settings (Sergio et al., 2009; Germain and Arcese, 2014). Similar to the findings of Siefferman and Hill (2005b), we found that older female bluebirds tended to experience high fledging success; yet, our results suggest that occupancy is a better predictor of reproductive output than is female quality. This is contrary to the findings of Zabala and Zuberogoitia (2014), who found that individual quality better explained the variation in reproductive success than habitat quality among peregrine falcons (Falco peregrinus). However, like Germain and Arcese (2014) who studied small passerines (song sparrows; Melospiza melodia), we found that habitat and individual quality both contribute to reproductive output. Our best-suited model to explain reproductive output included habitat characteristics (both occupancy and openness) 
as well as female quality. Thus, it is important for managers of at-risk populations to consider both the habitat and individual characteristics to determine what site-specific parameters best increase reproductive success.

Our results suggest that historical occupancy is an accurate and reliable proxy of territory quality in cavity-nesting species. Supported by the findings of Cooper et al. (2005), who investigated variation in reproductive output along a range-wide geographic scale, our data suggests that birds that produce more clutches per year and larger clutches experience the highest reproductive success. It is likely that habitat quality directly influences reproductive success because birds that bred in high occupancy locations were much more likely to produce two successful broods in the season. Eastern bluebirds appear to accurately assess territory quality because the locations with the highest occupancy from year to year are the most productive locations. Additionally, bluebirds may be selecting breeding territories based on physical habitat parameters (i.e., openness of the territory); particularly when they must cope with high tree swallow competition. Bluebirds arrive and settle prior to tree swallows at our field sites and they may use openness cues to estimate how likely they are to encounter tree swallow competition later in the breeding season, potentially in an attempt to avoid swallows. However, it is possible that, in late winter, many more bluebirds settle on territories but because of early season interactions with tree swallows, they abandon these less open territories. These abandoned nest sites maybe more likely to have been defended by younger, less experienced or lower quality bluebirds. Unfortunately, without detailed early spring behavioral observations, we cannot properly address these alternatives. Whatever the mechanism, our data suggest clear tradeoffs between spatial habitat parameters and differing degrees of interspecific competition. If researchers are to use occupancy as a proxy of habitat quality in their particular study system, they should also take into account direct measures of habitat quality as well as potential competition from sympatric species. Indeed, the consequences of species coexistence may be reduced reproductive success (Martin and Martin, 2001), and thus, competition is an important variable that should be taken into account for successful population management. This is the first study, to our knowledge, to relate easily obtainable occupancy rates to spatial habitat parameters and reproductive success in varying degrees of interspecific competition. We believe that these relatively simple metrics may serve as useful tools to managers to determine the highest quality territories when assessing when and where to allocate resources for successful conservation.

The methods presented here are not avian specific and may be applied to a wide range of taxa. Occupancy rates provide a framework for researchers to implement conservation of rich and productive habitats. Land use/land cover data as a proxy of physical habitat is easily obtained from remotely sensed sources. While intraspecific densities may lower the realized habitat quality (Johnson, 2007), our data suggest that interspecific competition can have similar impacts and must be taken into account when determining overall habitat quality. As a first step in conservation decisions, managers and researchers should look for correlations between habitat use and physical characteristics of the habitat. If such correlations are found, a large-scale site suitability analysis can be conducted that contains a thorough investigation of community structure and interactions between species. Doing so could allow land managers to avoid habitat sinks (Dias, 1996), or areas of poor quality, while focusing the majority of their efforts in areas with increased productivity. Measuring habitat quality is a necessary precursor for discerning the effects of landscape composition on the success of species (Johnson, 2007) and the methods presented in our study demonstrate the necessary guidelines for landscape scale conservation based on easily obtainable information about territory use and land cover.

\section{ACKNOWLEDGMENTS}

We thank our volunteer field crew: Patrick Latimer and Stephanie Stegemoller. We also thank Alexandra Bentz, Jordan Holcomb, Michael Gangloff, Steve Seagle, members of the SieffermanGangloff lab of Appalachian State University, Peter Schausberger, and three anonymous reviewers for providing useful suggestions on earlier drafts of this manuscript as well as Jeff Colby for assistance with GIS analyses. Finally, we are grateful for Appalachian State's Research Institute for Environment, Energy, and Economics (RIEEE) for providing funding.

\section{REFERENCES}

Askenmo, C. E. H. (1984). Polygyny and nest site selection in the pied flycatcher. Anim. Behav. 32, 972-980. doi: 10.1016/S0003-3472(84)80209-2

Burnham, K. P., and Anderson, D. R. (2002). Model Selection and Multimodel Inference: a Practical Information-Theoretic Approach, 2nd Edn. New York, NY: Springer.

Clobert, J., Danchin, E., Dhondt, A. A., and Nichols, J. D. (2001). Dispersal. Oxford: Oxford University Press.

Cooper, C. B., Hochachka, W. M., and Dhondt, A. A. (2005). Latitudinal trends in within-year reoccupation of nest boxes and their implications. J. Avian Biol. 36, 31-39. doi: 10.1111/j.0908-8857.2005.03319.x

Dawson, R. D., and Bortolotti, G. R. (2006). Fire in the boreal forest: proximate effects on reproduction and long-term consequences for territory occupancy of American kestrels. Ecoscience 13, 75-81. doi: 10.2980/11956860(2006)13[75:FITBFP]2.0.CO;2

Dias, P. C. (1996). Sources and sinks in population biology. Trends Ecol. Evol. 11, 326-330. doi: 10.1016/0169-5347(96)10037-9

Doligez, B., Danchin, E., and Clobert, J. (2002). Public information and breeding habitat selection in a wild bird population. Science 297, 1168-1170. doi: 10.1126/science. 1072838

Doran, P. J., and Holmes, R. T. (2005). Habitat occupancy patterns of a forest dwelling songbird: causes and consequences. Can. J. Zool. 83, 1297-1305. doi: $10.1139 / \mathrm{z} 05-127$

ESRI. (2011). ArcGIS Desktop: Release 10. Redlands, CA: Environmental Research Institute.

Fretwell, S. D. (1972). Populations in a Seasonal Environment. Princeton, NJ: Princeton University Press.

Germain, R., and Arcese, P. (2014). Distinguishing individual quality from habitat preference and quality in a territorial passerine. Ecology 95, 436-445. doi: 10.1890/13-0467.1

Gowaty, P. A., and Plissner, J. H. (1998). Eastern Bluebird (Sialia sialis), The Birds of North America Online ed A. Poole. Ithaca: Cornell Lab of Ornithology. Available online at: http://bna.birds.cornell.edu/bna/species/381

Harris, M. R., and Siefferman, L. (2014). Interspecific competition influences fitness benefits of assortative mating for territorial aggression in eastern bluebirds (Sialia sialis). PLoS ONE 9:e88668. doi: 10.1371/journal.pone.0088668

Hersey, F. S. (1933). Notes on tree swallows and bluebirds. Auk 50, 109-110. doi: $10.2307 / 4076583$

IBM Corp. (2012). IBM SPSS Statistics for Windows, Version 21.0. Armonk, NY: IBM Corp. 
Jakob, E. M., Marshall, S. D., and Uetz, G. W. (1996). Estimating fitness: a comparison of body condition indices. Oikos 77, 61-67. doi: 10.2307/3545585

Janiszewski, T., Minias, P., and Wojciechowski, Z. (2013). Occupancy reliably reflects territory quality in a long-lived migratory bird, the white stork. J. Zool. 291, 178-184. doi: 10.1111/jzo.12059

Johnson, L. S. (1998). House Wren (Troglodytes aedon), The Birds of North America Online. ed A. Poole. Ithaca: Cornell Lab of Ornithology. Available online at: http://bna.birds.cornell.edu/bna/species/380

Johnson, M. D. (2007). Measuring habitat quality: a review. Condor 109, 489. doi: $10.1650 / 8347.1$

Kokko, H. (1999). Competition for early arrival in migratory birds. J. Anim. Ecol. 68, 940-950. doi: 10.1046/j.1365-2656.1999.00343.x

Komdeur, J. (1992). Importance of habitat saturation and territory quality for evolution of cooperative breeding in the Seychelles warbler. Nature 358, 493-495. doi: $10.1038 / 358493 \mathrm{a} 0$

Korpimaki, E. (1988). Effects of territory quality on occupancy, breeding performance and breeding dispersal in Tengmalm's owl. J. Anim. Ecol. 57, 97-108. doi: $10.2307 / 4766$

Kostrzewa, A. (1996). A comparative study of nest-site occupancy and breeding performance as indicators for nesting habitat quality in three European raptor species. Ethol. Ecol. Evol. 8, 1-18. doi: 10.1080/08927014.1996.9522931

Lee, D. S. (1993). Range expansion of the tree swallow, Tachycineta bicolor (Passeriformes: Hirundinidae), in the southeastern United States. Brimleyana 18, 103-113.

Lomnicki, A. (1988). Population Ecology of Individuals. Princeton, NJ: Princeton University Press.

Lozano, G. A., Perreault, S., and Lemon, R. E. (1996). Age, arrival date and reproductive success of male American redstarts Setophaga ruticilla. J. Avian Biol. 27, 164-170. doi: 10.2307/3677146

Martin, P., and Martin, T. (2001). Ecological and fitness consequences of species coexistence: a removal experiment with wood warblers. Ecology 82, 189-206. doi: 10.1890/0012-9658(2001)082[0189:EAFCOS]2.0.CO;2

Matthysen, E. (1990). Behavioral and ecological correlates of territory quality in the Eurasian Nuthatch (Sitta europaea). Auk 107, 86-95.

Muller, K. L., Stamps, J. A., Krishnan, V. V., and Willits, N. H. (1997). The effects of conspecific attraction and habitat quality on habitat selection in territorial birds (Troglodytes aedon). Am. Nat. 150, 650-661. doi: 10.1086/286087

Newton, I. (1991). Habitat variation and population regulation in Sparrowhawks. Ibis 133, 76-88. doi: 10.1111/j.1474-919X.1991.tb07671.x

Nilsson, S. (1987). Limitation and regulation of population density in the nuthatch Sitta europaea (Aves) breeding in natural cavities. J. Anim. Ecol. 56, 921-937. doi: $10.2307 / 4957$

Orians, G., and Wittenberger, J. (1991). Spatial and temporal scales in habitat selection. Am. Nat. 137, S29-S49. doi: 10.1086/285138

Parejo, D., White, J., and Danchin, E. (2007). Settlement decisions in blue tits: difference in the use of social information according to age and individual success. Naturwissenschaften 94, 749-757. doi: 10.1007/s00114-007-0253-Z

Penteriani, V., Gallardo, M., and Roche, P. (2002). Landscape structure and food supply affect eagle owl (Bubo bubo) density and breeding performance: a case of intra-population heterogeneity. J. Zool. 257, 365-372. doi: 10.1017/S0952836902000961

Pinkowski, B. C. (1977). Foraging behavior of the eastern bluebird. Wilson Bull. 89, 404-414.

Pitts, D. (1985). Identification of second-year and after-second-year eastern bluebirds. J. Field Biol. 56, 422-424.

Robertson, R. J., Stutchbury, B. J., and Cohen, R. R. (1992). Tree swallow (Tachycineta bicolor). The Birds of North America Online. ed A. Poole, Ithaca: Cornell Lab of Ornithology. Available online at: http://bna.birds.cornell.edu/ bna/species/011

Rosenzweig, M. (1991). Habitat selection and population interactions: the search for mechanism. Am. Nat. 137, S5-S28. doi: 10.1086/285137

Scales, J., Hyman, J., and Hughes, M. (2013). Fortune favours the aggressive: territory quality and behavioural syndromes in song sparrows, Melospiza melodia. Anim. Behav. 85, 441-451. doi: 10.1016/j.anbehav.2012.12.004

Sergio, F., Blas, J., Baos, R., Forero, M. G., Donázar, J. A., and Hiraldo, F. (2009). Short- and long-term consequences of individual and territory quality in a longlived bird. Oecologia 160, 507-514. doi: 10.1007/s00442-009-1314-0

Sergio, F., and Newton, I. (2003). Occupancy as a measure of territory quality. J. Anim. Ecol. 72, 857-865. doi: 10.1046/j.1365-2656.2003.00758.x

Siefferman, L., and Hill, G. E. (2005a). UV-blue structural coloration and competition for nestboxes in male eastern bluebirds. Anim. Behav. 69, 67-72. doi: 10.1016/j.anbehav.2003.12.026

Siefferman, L., and Hill, G. E. (2005b). Evidence for sexual selection on structural plumage coloration in female eastern bluebirds (Sialia sialis). Evolution 59, 1819-1828. doi: 10.1111/j.0014-3820.2005.tb01828.x

Wagner, S., Stegenga, S., and Hilton, B. Jr. (2002). First breeding records for tree swallows in South Carolina. Chat 66, 145-148.

Zabala, J., and Zuberogoitia, I. (2014). Individual quality explains variation in reproductive success better than territory quality in a long-lived territorial raptor. PLoS ONE 9:e90254. doi: 10.1371/journal.pone.0090254

Conflict of Interest Statement: The authors declare that the research was conducted in the absence of any commercial or financial relationships that could be construed as a potential conflict of interest.

Received: 22 August 2014; accepted: 08 October 2014; published online: 28 October 2014.

Citation: Jones JA, Harris MR and Siefferman L (2014) Physical habitat quality and interspecific competition interact to influence territory settlement and reproductive success in a cavity nesting bird. Front. Ecol. Evol. 2:71. doi: 10.3389/fevo.2014.00071 This article was submitted to Behavioral and Evolutionary Ecology, a section of the journal Frontiers in Ecology and Evolution.

Copyright (C) 2014 Jones, Harris and Siefferman. This is an open-access article distributed under the terms of the Creative Commons Attribution License (CC BY). The use, distribution or reproduction in other forums is permitted, provided the original author(s) or licensor are credited and that the original publication in this journal is cited, in accordance with accepted academic practice. No use, distribution or reproduction is permitted which does not comply with these terms. 